CLINICAL STUDY

\title{
Circulating leptin concentrations and ovarian function in polycystic ovary syndrome
}

\author{
I R Pirwany ${ }^{2}$, R Fleming, N Sattar ${ }^{1}$, I A Greer and A M Wallace ${ }^{1}$ \\ Department of Obstetrics and Gynecology, University of Glasgow, Royal Infirmary, 10 Alexandra Parade, Glasgow G31 2ER, UK, ${ }^{1}$ Department of \\ Biochemistry, Royal Infirmary, McEwen Building, Glasgow, UK and ${ }^{2}$ Department of Obstetrics and Gynecology, Division of Reproductive Endocrinology \\ and Infertility, McGill Reproductive Centre, Royal Victoria Hospital, Women's Pavillion, Montreal, Quebec, Canada \\ (Correspondence should be addressed to I R Pirwany, Department of Obstetrics and Gynecology, Division of Reproductive Endocrinology and Infertility, \\ McGill Reproductive Centre, Royal Victoria Hospital, Women's Pavillion, F6.58, 687 Pine Avenue West, Montreal, Quebec H3A 1A1, Canada; \\ Email: imran.pirwany@muhc.mcgill.ca)
}

\begin{abstract}
Objective: Polycystic ovary syndrome (PCOS) is characterized by ovarian dysfunction. Although the role of leptin in the control of reproduction is unclear, it may be involved in the control of ovulation. The aim of this cross-sectional study was to determine the relationship between circulating leptin concentrations, and anthropometric, metabolic and endocrine variables as well as to examine a possible role of leptin in ovarian dysfunction associated with PCOS.

Design: Prospective observational study.

Methods: Seventy-one subjects with PCOS and 23 body mass index (BMI)-matched control subjects were recruited from infertility clinics. The association between serum leptin concentrations and the above variables was measured outwith the luteal phase. A subgroup of 24 PCOS subjects underwent more frequent blood sampling to monitor follicular growth and ovulation. The association between variables was measured by univariate, multivariate and partial correlation analyses.

Results: Serum leptin concentrations were not different in subjects with PCOS and controls, and were strongly associated with BMI in both groups. Twelve patients ovulated during the study period. There was no significant difference in serum leptin concentrations between ovulatory and anovulatory subjects. The relationship between BMI and leptin was similar in both groups.

Conclusion: The results indicated that circulating leptin concentrations relate principally to total body fat in subjects with PCOS and controls, and that this is not associated with the facility for follicular development and ovulation in these patients.
\end{abstract}

European Journal of Endocrinology 145 289-294

\section{Introduction}

It has been demonstrated that leptin, the product of the $o b$ gene (1), is involved in the regulation of adiposity in mammals and may act as an endocrine signalling factor, or 'lipostat', linking nutritional status to the reproductive axis (2). Administration of leptin to leptindeficient $\mathrm{ob} / \mathrm{ob}$ mice corrects the delay in reproductive function (3) and restores fertility (4). In humans, a critical blood leptin concentration appears to be necessary to trigger the onset of ovarian activity (5). Furthermore, circulating leptin concentrations appear to be better predictors of menstrual function than body mass index (BMI), fat mass or percentage body fat (6).

At the level of the ovary, leptin has been shown to inhibit insulin-induced steroidogenesis from the bovine ovary (7). Human ovarian follicles have leptin receptors (8), their follicular cells express leptin mRNA at the time of dominant follicle selection (9), and granulosa cells have been shown to secrete leptin (10), indicating a likely role for leptin in normal ovarian physiology. Indeed, circulating leptin concentrations vary significantly during the menstrual cycle, with a detectable rise in the periovulatory phase and peak concentrations in the luteal phase of the cycle $(11,12)$, indicating that it plays a role in ovulation.

Polycystic ovary syndrome (PCOS) is a common disorder (13) characterized by menstrual dysfunction, obesity and oligo-anovulation. It is also associated with endocrine and metabolic derangements, characterized by hyperandrogenaemia, hypersecretion of lutenizing hormone (LH), and insulin resistance. The analogy of the disturbed reproductive function in the obese mouse and PCOS is attractive at first presentation. Indeed, the combination of obesity, insulin resistance and infertility in PCOS had led to the suggestion that leptin may play some role in the abnormal ovarian function observed in PCOS (14). A growing body of evidence, however, 
indicates that leptin secretion is not disturbed in women with PCOS, compared with weight-matched controls (15-19). Interestingly, some studies that have examined serum leptin concentrations during the luteal phase of the cycle (20) have failed to demonstrate a significant relationship between circulating leptin concentrations and menstrual cyclicity after adjusting for body fat mass. However, none of these studies has attempted to discriminate between the women with PCOS who are capable of spontaneous ovulation, and those who remain anovulatory. Given that many women with PCOS undergo spontaneous follicular development (21), it remains possible that leptin may be one of the factors influencing the incidence or frequency of these critical events.

The aim of this cross-sectional study was to determine the relationship between circulating leptin concentrations, and metabolic and endocrine factors and to examine a possible role of these factors in the degree of ovarian dysfunction, particularly the ability to undergo follicular maturation and ovulation in a group of subjects with PCOS.

\section{Materials and methods}

\section{Patients}

Subjects $(n=71)$ with PCOS were recruited from the infertility clinics at the Glasgow Royal Infirmary. PCOS was diagnosed in women with oligomenorrhoea (cycle length $>41$ days), associated with typical ovarian appearances by transvaginal ultrasound (22), yielding a characteristic endocrine profile. All the ultrasound examinations were performed transvaginally by one of the authors (IRP). Control subjects with unexplained infertility, normal menstrual rhythm and morphologically normal ovaries $(n=23)$ were recruited from the same sources.

All subjects had normal prolactin concentrations and normal thyroid function test results. Diabetes mellitus and late onset congenital adrenal hyperplasia were excluded in all patients by fasting blood glucose and $17 \alpha$-hydroxyprogesterone estimations respectively. No subject had taken any medications for the 2 months preceding the study.

The study was approved by the local Research Ethics Committee, and all subjects gave written informed consent.

\section{Sampling and assays}

Serum samples were taken from all subjects after an overnight fast of $12 \mathrm{~h}$, between 0830 and $0930 \mathrm{~h}$. In those women with a normal menstrual rhythm, serum samples were obtained in the follicular phase of the cycle (days 2-6 of the menstrual cycle) while, in women with oligomenorrhoea, samples were obtained at least 14 days following their last menstrual period, but outwith the luteal phase, confirmed by serum progesterone estimation. Blood was collected and harvested at $4{ }^{\circ} \mathrm{C}$ by low speed centrifugation and aliquots of serum for leptin determination and for hormonal analyses were stored at $-70{ }^{\circ} \mathrm{C}$ until analysis. Anthropometric measurements were made by the same trained observer using standard techniques as described previously (WHO) (37). BMI was calculated as: weight $(\mathrm{kg}) /$ height $(\mathrm{m})^{2}$.

Serum leptin concentrations were measured in duplicate using a ${ }^{125} \mathrm{I}$ radioimmunoassay (Linco Research, Inc., St Charles, MO, USA) (23). The intra and interassay coefficients of variation were $5.8 \%$ and $6.5 \%$ respectively over the sample concentration range. Oestradiol $\left(E_{2}\right)$ and progesterone were measured using a competitive fluoroimmunoassay (Delphia, Wallac Ltd, Turku, Finland). Testosterone was measured using a competitive radioimmunoassay (Coat-A-Count T; DPC, Los Angeles, CA, USA). LH and sex hormone binding globulin (SHBG) were assayed using specific noncompetitive sandwich fluoroimmunoassays (Delfia hLH and Delfia SHBG; Wallac Ltd). The free androgen index (FAI) was calculated as testosterone concentration $(\mathrm{nmol} / \mathrm{l}) \times 100$, divided by SHBG concentration (nmol/l). Plasma insulin was measured using a competitive radioimmunoassay (Coat-A-Count I).

\section{Ovarian function assessment}

Twenty-four subjects with PCOS underwent more frequent blood sampling (three times a week for 5 weeks) to monitor follicular growth $\left(\mathrm{E}_{2}\right)$ and ovulation, with the investigation window starting at least 14 days following a menstrual bleed. Luteinization and ovulation were considered to have taken place when serum progesterone concentration exceeded $2.5 \mathrm{ng} / \mathrm{ml}$, following an LH surge. Two groups of PCOS subjects could thus be identified; those capable of undergoing follicular growth, maturation and ovulation, and those who demonstrated anovulation. Serum leptin concentrations were measured in the ovulatory blood sample in the case of women who demonstrated ovulation, and the corresponding sample in women who remained anovulatory.

\section{Statistical analyses}

Distribution of all variables was assessed for normality by Shapiro-Wilks test. The following variables, not normally distributed were $\log \left(\log _{\mathrm{e}}\right)$ transformed: leptin, fasting insulin (FI), testosterone, $\mathrm{E}_{2}$, progesterone and SHBG, while all other variables were analyzed untransformed. Independent sample $t$-tests were used to test for the difference in means of continuous normal or log normally distributed variables. Results for normally distributed variables are shown as means \pm S.D.; geometric mean (range) is quoted for log-transformed variables. 
The associations between variables were examined by simple linear regression. Partial correlations were performed to determine the association of leptin to anthropometric, metabolic and endocrine variables after controlling for BMI. Multivariate analyses were employed to determine the extent to which age, BMI, waist circumference (WC), waist to hip ratio (WHR) and FI related to variations in leptin concentrations. In multivariate regression, variables identified as significant predictor variables by simple linear regression were entered; when there was significant interaction between the explanatory variables, e.g. between WC and WHR, or BMI, multivariate models included only one of these variables. Adjusted $\mathrm{R}^{2}$ was calculated, which takes into account the number of predictor variables. Statistical analyses were performed using SPSS for Windows (SPSS Inc., Chicago, IL, USA).

\section{Results}

Table 1 demonstrates that although there was no significant difference between the two groups in BMI, the WC and WHR were significantly higher in the women with PCOS. The women with PCOS had higher circulating concentrations of $\mathrm{LH}$ and testosterone, and higher FAI compared with the control group. In contrast, FI and circulating leptin concentrations were not different between the two groups.

Table 2 shows that BMI and WC were strongly correlated with circulating leptin concentrations in both groups of patients. In contrast, the correlations between circulating leptin concentrations and those of FI and FAI were significant only in the PCOS group. After correcting for BMI, these correlation coefficients were no longer significant in either group except WC which remained significantly correlated in the PCOS group.

\section{Leptin and ovarian activity}

Circulating leptin concentrations were determined in 24 BMI-matched hyperandrogenic PCOS subjects who

Table 1 Subject characteristics and cross-sectional endocrine and metabolic variables in the study groups. The geometric mean is given with the range in parentheses.

\begin{tabular}{lcc}
\hline & $\begin{array}{c}\text { Normal ovaries } \\
(n=23)\end{array}$ & \multicolumn{1}{c}{$\begin{array}{c}\text { PCOS } \\
(n=71)\end{array}$} \\
\hline Age (years) $\dagger$ & $28.6(3.9)$ & $27.8(4.3)$ \\
BMl $\left(\mathrm{kg} / \mathrm{m}^{2}\right) \dagger$ & $28.22(6.17)$ & $28.61(5.98)$ \\
WC $(\mathrm{cm}) \dagger$ & $81.78(11.05)$ & $87.42(13.41)^{\star}$ \\
WHRt & $0.77(0.05)$ & $0.83(0.06)^{\star *}$ \\
LH (U/l) & $5.60(1.99-31.50)$ & $8.57(0.19-22.66)^{\star *}$ \\
Testosterone (nmol/l) & $1.38(0.34-3.08)$ & $3.36(0.34-23.15)^{\star *}$ \\
FAl & $0.92(0.19-3.89)$ & $2.70(0.26-12.30)^{\star *}$ \\
FI (IU/l) & $9.97(3.0-24.04)$ & $11.05(3.0-51.93)$ \\
Leptin $(\mu \mathrm{g} / \mathrm{l})$ & $19.20(1.28-58.55)$ & $19.91(3.32-66.02)$
\end{tabular}

$\dagger$ Values are means with S.D. shown in parentheses.

${ }^{\star} P<0.05,{ }^{* *} P<0.01$
Table 2 Linear correlation coefficient $(\mathrm{R})$ and partial correlation coefficient $\left(R_{p}\right)$ analyses of the significant variables with circulating leptin, after controlling for BMI.

\begin{tabular}{lccccc}
\hline & \multicolumn{2}{c}{ Controls $(n=23)$} & & \multicolumn{2}{c}{$\mathrm{PCOS}(n=71)$} \\
\cline { 2 - 3 } \cline { 6 - 6 } & $\mathrm{R}$ & $\mathrm{R}_{\mathrm{p}}$ & & $\mathrm{R}$ & $\mathrm{R}_{\mathrm{p}}$ \\
\hline BMI & $0.63^{\star *}$ & & & $0.79^{\star \star}$ & \\
WC & $0.65^{\star \star}$ & 0.24 & & $0.75^{\star \star}$ & $0.26^{\star}$ \\
WHR & 0.34 & 0.17 & & -0.46 & 0.12 \\
Testosterone & 0.22 & 0.17 & & -0.04 & 0.12 \\
LH & -0.23 & -0.20 & & -0.11 & 0.03 \\
FI & 0.17 & -0.11 & & $0.61^{\star \star}$ & 0.23 \\
FAI & 0.38 & 0.11 & & $0.35^{\star \star}$ & 0.20 \\
\hline
\end{tabular}

${ }^{*} P<0.05,{ }^{* *} P<0.01$

were monitored for follicular development over a 5-week period. Spontaneous ovulation was recorded in $50 \%$ of patients $(n=12)$. Table 3 shows the anthropometric and metabolic variables in these two groups. Subjects who did not ovulate during the observation period had higher BMI than those who ovulated, although the difference was not statistically significant. Nor were significant differences observed in the concentrations of LH, testosterone, FI or leptin concentrations between the two groups. In keeping with follicular maturation, $\mathrm{E}_{2}$ concentrations were higher in ovulating subjects. Figure 1 shows that the distribution of leptin concentrations was similar in both the lean (BMI $<25)$ and obese patients (BMI $>=25$ ) who underwent follicular maturation and ovulation compared with those who remained anovulatory. BMI was the most important correlate of circulating leptin concentrations in both groups of patients, and explained $72 \%\left(\mathrm{R}^{2}=0.72 ; P<0.0001\right)$ and $55 \%$ $\left(\mathrm{R}^{2}=0.55 ; \quad P=0.004\right)$ of the variability in the concentration of leptin in ovulating and non-ovulating subjects respectively. These data indicate that circulating leptin concentrations appear to be unrelated to the facility of follicular development and ovulation.

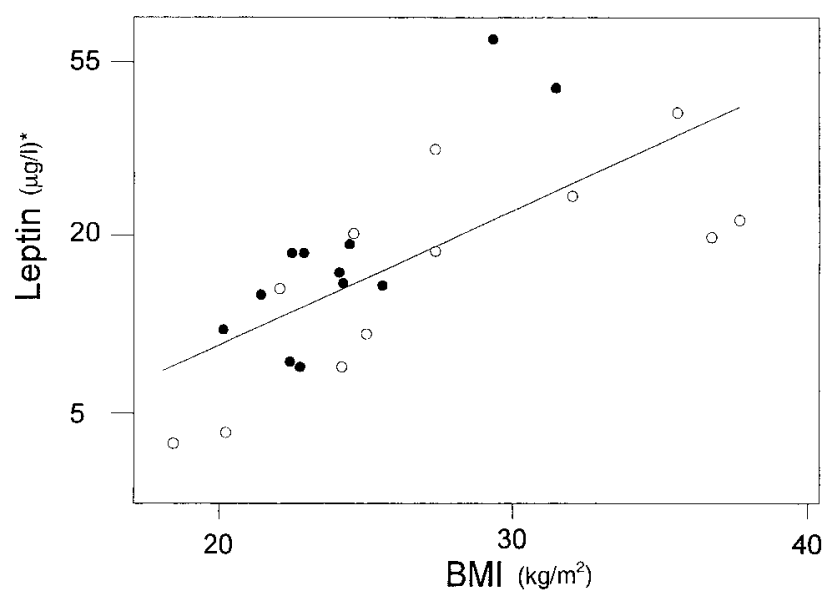

Figure 1 Distribution of $\log _{\mathrm{e}}$ leptin in lean and obese ovulating ( and non-ovulating $(O)$ study groups. ${ }^{*} \log$ value. 
Table 3 Subject characteristics, and anthropometric, endocrine and metabolic variables in subjects monitored for ovulation. The geometric mean is given with the range in parentheses.

\begin{tabular}{lcc}
\hline & Non-ovulators $(n=12)$ & Ovulators $(n=12)$ \\
\hline $\mathrm{BMI}\left(\mathrm{kg} / \mathrm{m}^{2}\right) \dagger$ & $27.47(6.71)$ & $24.27(3.23)$ \\
WC $(\mathrm{cm}) \dagger$ & $88.16(14.54)$ & $80.08(8.97)$ \\
WHR† & $0.87(0.08)$ & $0.82(0.05)$ \\
$\mathrm{E}_{2}(\mathrm{pmol} / \mathrm{l})$ & $160.0(91.7-235.1)$ & $287.3(172.45-544.6)^{\star *}$ \\
$\mathrm{LH}(\mu \mathrm{g} / \mathrm{l})$ & $11.14(3.78-22.42)$ & $9.75(4.05-22.64)$ \\
Testosterone $(\mathrm{nmol} / \mathrm{l})$ & $8.63(4.95-23.15)$ & $8.24(3.67-11.71)$ \\
$\mathrm{FI}(\mathrm{IU} / \mathrm{l})$ & $6.98(3.0-29.07)$ & $3.40(1.04-7.02)$ \\
FAl & $5.42(1.18-12.30)$ & $17.69(9.02-66.02)$ \\
Leptin $(\mu \mathrm{g} / \mathrm{l})$ & $15.61(4.48-42.52)$ & \\
\hline
\end{tabular}

†Values are means with S.D. shown in parentheses. ${ }^{* *} P<0.01$.

\section{Discussion}

In this cross-sectional study we observed that women with PCOS had higher WHR, LH, testosterone, FI and FAI, and lower concentrations of SHBG than control women with a normal menstrual rhythm and morphologically normal ovaries. BMI was the most important determinant of circulating leptin concentrations in both groups of patients $(24,25)$. In accord with other published studies in PCOS subjects, serum leptin concentrations were not different between subjects with PCOS and BMI-matched controls (16-19, 26). Additionally, the results of the present study demonstrated that serum leptin concentrations were not different between ovulatory and anovulatory groups of PCOS subjects, indicating that serum leptin may not play an important role in determining the facility for ovulation in this group of patients.

We noted a wide variation in leptin concentration in subjects with PCOS and in controls with similar ranges of body mass; moreover, the relationship between circulating leptin concentration and BMI was similar in both these groups of subjects. However, BMImatched women with PCOS had a higher WC compared with control subjects, and WC was strongly and positively correlated with leptin concentrations in both groups. This correlation remained significant in the PCOS group after correcting for BMI. Given that $\mathrm{WC}$ is considered to be a reliable anthropometric index of intra-abdominal fat accumulation and associated insulin resistance in subjects with PCOS (27), this suggests a possible contributory effect of decreased insulin sensitivity upon circulating leptin concentrations in this group of patients.

In the present study we used FI concentrations as a surrogate measure of insulin sensitivity. The relationship between circulating leptin concentration and insulin resistance in subjects with PCOS appears to be influenced by body mass, since it is no longer significant after adjusting for body fat mass $(19,24,26)$. The effects of decreasing insulin resistance by insulin-sensitizing agents have been inconclusive, and demonstrate that whereas metformin (28) and diazoxide (29) appear to decrease circulating leptin concentrations in parallel with the improvement in insulin sensitivity, troglitazone, which is considered to be a more effective insulin-sensitizing agent, does not appear to influence plasma leptin concentrations (17). It is possible that more robust measures of insulin sensitivity in this study may have revealed a greater difference in insulin resistance in the study groups. Additionally, the cross-sectional design of this study precludes any inference on the effect of insulin resistance on modulating circulating leptin concentrations.

Insulin resistance is thought to play a pivotal role in the aetiology of PCOS and may be related to the hyperandrogenaemia in these patients $(30,31)$. Furthermore, insulin has also been shown to stimulate leptin secretion in humans (32). Our group of PCOS subjects, despite showing a tendency for hyperinsulinaemia, had circulating leptin concentrations that were not different from the control group. Moreover, the relationship between leptin and FI was not significant after correction for BMI in either group, indicating that the relationship between leptin and insulin concentrations is likely to be governed by total adiposity $(19,26)$.

Elevated serum leptin concentrations may play a role in arresting follicular development in certain women with PCOS (9). It is possible that in humans circulating leptin may influence ovarian function either by its direct affect on the ovary, or indirectly by modulation of insulin action or LH secretion. Leptin receptors have been identified in both granulosa and theca cells of the human ovarian follicle $(8,33)$, and granulosa cells have been shown to secrete leptin (10), indicating a direct paracrine role for leptin at the ovarian follicular level (33). Interestingly, it has been suggested that leptin may indirectly influence ovarian follicular activity by affecting LH release. Indeed, the diurnal variation in leptin secretion appears to be synchronous with LH secretion, suggesting that the nocturnal rise in leptin may determine the change in the preovulatory LH profile (34).

Our data, however, do not support a role for circulating leptin in the disordered ovulation in subjects 
with PCOS. In subjects who were monitored for follicular growth, and who demonstrated follicular maturation and ovulation, there appeared to be no distinguishing concentration of circulating leptin. This applied to both lean and obese patients. Furthermore, the relationships between leptin and BMI were the same in ovulatory and anovulatory patients with oligomenorrhoea, implying that any role of leptin upon ovarian function would be mediated through tissue sensitivity at the follicular level, since no circulating leptin concentrations could be deemed pathological with respect to follicular growth.

Although our results do not implicate leptin in anovulation related to PCOS it is well documented that leptin plays a permissive role in anovulation in animal experiments. For instance, administration of leptin to starving mice prevents the starvation-induced delay in anovulation (35) and administration of leptin to the ob/ob mouse restores fertility (36). In such extreme situations, leptin does appear to have a facilitatory role in ovulation, and a contributory role in the promotion of pregnancy.

In conclusion, our data show that circulating total leptin concentrations in women with PCOS are similar to BMI-matched controls, and that there was no role for circulating leptin in influencing follicular maturation and ovulation. A progressive increase in leptin concentration and a significant independent correlation of leptin concentration with BMI was observed in both PCOS and control subjects. These results preclude a role for circulating leptin in the impaired follicular growth and abnormal ovarian function associated with PCOS.

\section{References}

1 Zhang Y, Proenca R, Maffei M, Barone M, Leopold L \& Friedman JM. Positional cloning of the mouse obese gene and its human homologue. Nature 1994372 425-432.

2 Barash IA, Cheung CC, Weigle DS, Ren H, Kabigting EB, Kuijper JL et al. Leptin is a metabolic signal to the reproductive system. Endocrinology 1996137 3144-3147.

3 Chehab FF, Mounzih K, Lu R \& Lim ME. Early onset of reproductive function in normal female mice treated with leptin. Science $199727588-90$.

4 Chehab FF, Lim ME \& Lu R. Correction of the sterility defect in homozygous obese female mice by treatment with the human recombinant leptin. Nature Genetics 199612 318-320.

5 Matkovic V, Ilich JZ, Skugor M, Badenhop NE, Goel P, Clairmont A et al. Leptin is inversely related to age at menarche in human females. Journal of Clinical Endocrinology and Metabolism $1997 \mathbf{8 2}$ 3239-3245.

6 Kopp W, Blum WF, von Prittwitz S, Ziegler A, Lubbert H, Emons G et al. Low leptin levels predict amenorrhea in underweight and eating disordered females. Molecular Psychiatry 19972 335340.

7 Spicer LJ \& Francisco CC. The adipose obese gene product, leptin: evidence of a direct inhibitory role in ovarian function. Endocrinology 1997138 3374-3379.

8 Cioffi JA, Shafer AW, Zupancic TJ, Smith-Gbur J, Mikhail A, Platika D et al. Novel B219/OB receptor isoforms: possible role of leptin in hematopoiesis and reproduction. Nature Medicine 1996 2 585-589.
9 Agarwal SJ, Vogel K, Weitsman SR \& Magoffin DA. Leptin antagonizes the insulin-like growth factor-I augmentation of steroidogenesis in granulosa and theca cells of the human ovary. Journal of Clinical Endocrinology and Metabolism $1999841072-$ 1076.

10 Antczak M, Blerkom JV \& Clark A. A novel mechanism of vascular endothelial growth factor, leptin and transforming growth factor- $\beta 2$ sequestration in a subpopulation of human ovarian follicle cells. Human Reproduction 199712 2226-2234.

11 Shimizu H, Shimomura Y, Nakanishi Y, Futawatari T, Ohtani K, Sato $\mathrm{N}$ et al. Estrogen increases in vivo leptin production in rats and human subjects. Journal of Endocrinology 1997154 285-292.

12 Hardie L, Trayhurn P, Abramovich D \& Fowler P. Circulating leptin in women: a longitudinal study in the menstrual cycle and during pregnancy. Clinical Endocrinology 199747 101-106.

13 Franks S. Polycystic ovary syndrome. New England Journal of Medicine $1995333853-861$.

14 Brzechffa PR, Jakimiuk AJ, Agarwal SK, Weitsman SR, Buyalos RP \& Magoffin DA. Serum immunoreactive leptin concentrations in women with polycystic ovary syndrome. Journal of Clinical Endocrinology and Metabolism $1996 \mathbf{8 1}$ 4166-4169.

15 Chapman IM, Wittert GA \& Norman RJ. Circulating leptin concentrations in polycystic ovary syndrome: relation to anthropometric and metabolic parameters. Clinical Endocrinology 199746 175-181.

16 Laughlin GA, Morales AJ \& Yen SS. Serum leptin levels in women with polycystic ovary syndrome: the role of insulin resistance/ hyperinsulinemia. Journal of Clinical Endocrinology and Metabolism $1997821692-1696$.

17 Mantzoros CS, Dunaif A \& Flier JS. Leptin concentrations in the polycystic ovary syndrome. Journal of Clinical Endocrinology and Metabolism $1997 \mathbf{8 2} 1687-1691$.

18 Rouru J, Anttila L, Koskinen P, Penttila TA, Irjala K, Huupponen $\mathrm{R}$ et al. Serum leptin concentrations in women with polycystic ovary syndrome. Journal of Clinical Endocrinology and Metabolism $1997 \mathbf{8 2} 1697-1700$.

19 Gennarelli G, Holte J, Wide L, Berne C \& Lithell H. Is there a role for leptin in the endocrine and metabolic aberrations of polycystic ovary syndrome? Human Reproduction $1998 \mathbf{1 3}$ 535-541.

20 Teirmaa T, Luukkaa V, Rouru J, Koulu M \& Huupponen R. Correlation between circulating leptin and luteinizing hormone during the menstrual cycle in normal-weight women. European Journal of Endocrinology 1998139 190-194.

21 Fleming R, McQueen D, Yates RW \& Coutts JR. Spontaneous follicular and luteal function in infertile women with oligomenorrhoea: role of luteinizing hormone. Clinical Endocrinology $199543735-739$.

22 Adams J, Polson DW \& Franks S. Prevalence of polycystic ovaries in women with anovulation and idiopathic hirsutism. British Medical Journal (Clinical Research Edition) 1986293 355-359.

23 Björntorp P. The android woman - a risky condition. Journal of Internal Medicine 1996239 105-110.

24 Dagogo-Jack S, Fanelli C, Paramore D, Brothers J \& Landt M. Plasma leptin and insulin relationships in obese and nonobese humans. Diabetes 199645 695-698.

25 Ma Z, Gingerich RL, Santiago JV, Klein S, Smith CH \& Landt M. Radioimmunoassay of leptin in human plasma. Clinical Chemistry $199642942-946$.

26 Chapman IM, Wittert GA \& Norman RJ. Circulating leptin concentrations in polycystic ovary syndrome: relation to anthropometric and metabolic parameters. Clinical Endocrinology 199746 175-181.

27 Pouliot MC, Després JP, Lemieux S, Moorjani S, Bouchard C, Tremblay A et al. Waist circumference and abdominal sagittal diameter: best simple anthropometric indexes of abdominal visceral adipose tissue accumulation and related cardiovascular risk in men and women. American Journal of Cardiology 199473 460-468. 
28 Morin-Papunen LC, Koivunen RM, Tomas C, Ruokonen A \& Martikainen HK. Decreased serum leptin concentrations during metformin therapy in obese women with polycystic ovary syndrome. Journal of Clinical Endocrinology and Metabolism 1998 $832566-2568$.

29 Krassas GE, Kaltsas TT, Pontikides N, Jacobs H, Blum W \& Messinis I. Leptin levels in women with polycystic ovary syndrome before and after treatment with diazoxide. European Journal of Endocrinology 1998139 184-189.

30 Chang RJ, Nakamura RM, Judd HL \& Kaplan SA. Insulin resistance in nonobese patients with polycystic ovarian disease. Journal of Clinical Endocrinology and Metabolism 198357 356-359.

31 Dunaif A, Segal KR, Shelley DR, Green G, Dobrjansky A \& Licholai T. Evidence for distinctive and intrinsic defects in insulin action in polycystic ovary syndrome. Diabetes 199241 1257-1266.

32 Cusin I, Sainsbury A, Doyle P, Rohner-Jeanrenaud F \& Jeanrenaud B. The ob gene and insulin. A relationship leading to clues to the understanding of obesity. Diabetes $1995 \mathbf{4 4} 1467-$ 1470 .

33 Karlsson C, Lindell K, Svensson E, Bergh C, Lind P, Billig H et al. Expression of functional leptin receptors in the human ovary.
Journal of Clinical Endocrinology and Metabolism 199782 41444148.

34 Licinio J, Negrao AB, Mantzoros C, Kaklamani V, Wong ML, Bongiorno PB et al. Synchronicity of frequently sampled, 24-h concentrations of circulating leptin, luteinizing hormone, and estradiol in healthy women. PNAS 199895 2541-2546.

35 Ahima RS, Prabakaran D, Mantzoros C, Qu D, Lowell B, MaratosFlier E et al. Role of leptin in the neuroendocrine response to fasting. Nature $1996 \mathbf{3 8 2} 250-252$.

36 Chehab FF, Lim ME \& Lu R. Correction of the sterility defect in homozygous obese female mice by treatment with the human recombinant leptin. Nature Genetics 199612 318-320.

37 Pirwany IR, Fleming R, Greer IA, Packard CJ \& Sattar N. Lipids and lipoprotein subfractions in women with POCS: relationship to metabolic and endocrine parameters. Clinical Endocrinology 200154 447-453.

Received 6 December 2000

Accepted 4 May 2001 